\title{
Malignant Glomus Tumor
}

National Cancer Institute

\section{Source}

National Cancer Institute. Malignant Glomus Tumor. NCI Thesaurus. Code C4221.

A very rare morphologic variant of glomus tumor with a size greater than $2 \mathrm{~cm}$. The tumor arises in subfascial or visceral tissues. It is characterized by the presence of atypical mitotic figures, or marked nuclear atypia, or the combination of both. It has an aggressive clinical course. 